\title{
Using Design to Support the Creation of Street Art: A three-phase experiment supported by the DDArtS system
}

\author{
Paris Xyntarianos-Tsiropinas \\ University of the Aegean \\ Department of Products and Systems \\ Design and Engineering \\ 2 Konstantinoupoleos st. Hermoupolis, \\ Syros, Greece \\ parisxt@aegean.gr
}

\author{
Thomas Spyrou \\ University of the Aegean \\ Department of Products and Systems \\ Design and Engineering \\ 2 Konstantinoupoleos st. Hermoupolis, \\ Syros, Greece \\ tsp@aegean.gr
}

\author{
Konstantinos Bailas \\ University of the Aegean \\ Department of Products and Systems \\ Design and Engineering \\ 2 Konstantinoupoleos st. Hermoupolis, \\ Syros, Greece \\ kbail@aegean.gr
}

\begin{abstract}
The Digitally Drawn Art System is the result of on-going doctoral research on Street Art and Design, which has been running for the past three years in the Department of Product and Systems Design and Engineering (D.P.S.D.E.) of the University of the Aegean. In this paper, the latest version of the DDArtS system (version 3) will be used for the first time in a test performed in realworld conditions with the purpose of generating a large-scale outdoor mural. The leading ambition of this doctoral research in general, as well as of this specific experiment, is to investigate whether the use of the design can provide an auxiliary role in the creation of Street Art. In this regard, the project is divided in three main phases, the objective of each phase is to complete the same mural, but in a different way each time: in the first phase, a group of undergraduate students of the D.P.S.D.E. painted the mural using existing traditional techniques to transfer the original design from small to large scale on a wall. In the second phase, one of the authors, an experienced street artist, pained the same mural directly on the wall, without using measurement or transfer techniques. In the third phase, the students and the artist painted the mural, only this time based on an outline sketch generated by the DDArtS system. The completed murals are compared in terms of colour and line quality, but also in relation to the original design. The completion time of each phase will also be documented, as well as the quantity of resources used for each phase and the degree of difficulty during the execution of each mural project. For this purpose, commentary from the participants' experience before, during and after the completion of the three phases of the experiment is included.
\end{abstract}

Design. Street art. Spray paint. Murals. Mechanics. Systems.

\section{INTRODUCTION}

In the third year of study for the doctoral dissertation in the Department of Products and Systems Design and Engineering (D.P.S.D.E.) of the University of the Aegean, the growing and growing experimentation and testing with the Digitally Drawn Art System is becoming an imperative. In his PhD thesis, Paris XyntarianosTsiropinas, one of the authors, focuses on the extent and depth of the interplay between Street Art and Design. The DDArtS system is one of the derivatives of this research. For more information on the history of DDArtS evolution and its functionality, one can look for the two previous articles presented in EVA 2016 and 2017 (Xyntarianos-Tsiropinas et al. 2016, 2017).
The aforementioned experiments using DDArtS are at this stage necessary to better document the main objectives of the research plan. Especially in research cases revolving around Art and Design, the researcher has a dual role since he is also a practitioner. From a practitioner's point of view, the researcher identifies research problems in practical work, which he also tries to solve by methods of practice (Gray \& Malins 2004, pp.20-21), as happens with the present case study. Also, the practitioner-researcher tends to shift between roles, to approach the different research goals, where at times it is needed:

- The production of works of art and projects by participating in the creative process, 
- Self-observation through reflection on action or in action, but also through discussion with others,

- Observing others to place research within a context, as well as gaining other prospects,

- The coordination and facilitation of research projects and cooperative ventures in particular.

Street art is a fertile ground for developing cooperative projects, since values such as sociability and communication are fundamental elements of its core workflow. The Graffiti and Street Art culture not only constitutes of artists and scholars, but also by a wide range of professions and professionals. As Deitch, Gastman and Rose (2011, p.14) point out:

Today, Street Art is something that you will not only find in the streets but on the movie screen, in mass media and at auction.

However, research is crucial for every kind of artistic or design practice, as also reported by Noble and Bestley:

Research is an intrinsic aspect of design practice and an essential part of the activity of problem solving. The designer is involved in a constant process of enquiry (Noble \& Bestley 2005, p.18).

Under the scope of constant search for the interconnectivity between Design and Street Art, a three-phase experiment is being held, where the creation of three large murals is attempted, with the help of D.P.S.D.E. students and by using the DDArtS. Murals can be created individually or in groups. Many hands help in completing the artwork faster and such collective projects unite artists and their supporters (Blackshaw \& Farrely 2008, p.38). This whole research process takes the title of an experiment, since results on the execution time and the quality of the drafts sketches and the final murals will be gathered and evaluated, as well as views and empirical data gathered by the participants' experience.

The three different phases of the experiment will be analysed extensively, starting with the first phase, which is the creation of the first portrait draft sketch by the students of the D.P.S.D.E.

\section{A THREE-PHASE EXPERIMENT}

The experiment will evolve in three phases. The main objective of the experiment is:

- To study whether design and its derivatives have the potential to support the implementation of large-scale artwork.
In this case, the large-scale artworks will be three murals, which will depict the face of a young woman. The theme of the murals was selected by the group of the students who participated in the experiment. The students were urged to use an image that is neither too complex nor too simple. The purpose was to make something that was as challenging as needed but not disheartening. The three phases of the experiment are structured as follows:

(i) Creation of the draft sketch by the group of students of the D.P.S.D.E., using already known methods for transferring an image from small to large scale.

(ii) Creation of the same draft sketch by an experienced street artist, in this case one of the authors.

(iii) Creation of the draft sketch by the DDArtS system. Completion of the three artworks with the addition of colours, shadows and highlights.

After the draft painting on the wall, the group of students will be asked to complete their artwork, the artist his own, and together they will complete the artwork on the draft made by the DDArtS. The process will be photographed and captured from the beginning to the end. The different phases of the experiment will be documented in detail in this article.

The draft is "the alpha and omega" in the realization of any painting or street art project, from a canvas to a graffiti, and especially when dealing with large-scale artworks. Many artists work in complete freedom - without measuring the surface, or with little reliance on their drafts. However, when the copying of a predetermined subject is attempted, the use of a draft is necessary to allow for the correct arrangement of the image elements in regard to its dimensions and individual components and ultimately to make a correct copy.

\subsection{Experiment objectives}

The final drafts will be compared to each other to see which one is closer to the original photo and the digitally traced image. The drafts will be measured and compared to each other according to the following quantitative and qualitative factors:

- The time required for their creation (quantitative).

- Their similarity to the original design (quantitative).

- The "cleanliness" of the lines (quantitative).

- How much help they were to the creation of the final artwork (qualitative). 
As mentioned, the DDArtS draft will be painted into a mural by the team of students together with the street artist. This way, they will be able to comment on whether the draft was a good basis for the completion of painting.

As noted, from the above criteria, only the final one is qualitative. This means that in order to answer how much the drafts have supported the final painting the participants need to be interviewed. Their observations and comments on the process will be the testimony and the main lead to evaluate the last criterion.

While the specifics about the creation time and quality of the final murals will be documented, they will not be analysed on this paper. The contributors will be free to work on the final mural without having the limitation to present an exact copy of the reference image. What matters most in this experiment, and to art and street art in general, is not the faithful replication of an image by building a "mural printer" or a "fresco printer" for example, but to design a system that will support the artist on creating street artworks.

Therefore, the final works will be compared with each other only in terms of how satisfied the contributors are with their work, while supported by the draft sketch.

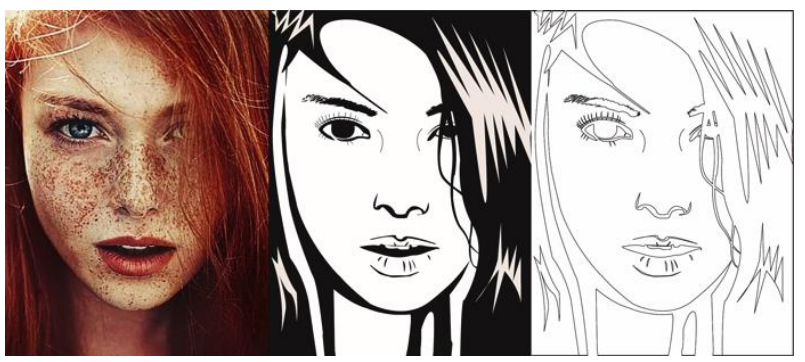

Figure 1: From left to right: a) the original image from the web, b) the traced image and c) the outlines.

\subsection{Creation of the draft sketch by the group of students}

The group of students selected for the experiment consisted of six members, all of which were 20year-old girls. At the time these lines were written, they were on the $4^{\text {th }}$ semester of their undergraduate degree and they were chosen because of their love for street art and their desire to work on a project of this kind. Also, it was important to select design students, and not random people, because they are already keen on the very basics of design methodology. Also, their ambition to work by following design steps and guidelines, but without having former professional experience in street art would be very interesting in relation to the objectives of the experiment.
The group chose a photo of a young girl from the Internet, which was edited in Adobe Illustrator (Figure 1). During the editing, the image was traced and the outlines of the draft sketch that were to be painted on the wall were created. The students were given this set of instructions so that the draft would be the same for each of the three phases of the experiment and therefore it could be easily compared to one another.

The students of D.P.S.D.E. have been taught methods of transferring an image from a small to a large scale in the first semester of their studies. So, at this stage of the experiment, they would already know how to use tools and techniques like a grid, a transfer paper, a pounce pattern, a stencil, etc. In this case, they decided that the best way to carry out the creation of the draft was with a grid.

Initially, the wall was painted by the group of students in a light beige colour and minor repairs were made to the areas with severe wear and tear. It is worth noting that the chosen wall was not new, clean or plastered, but an old concrete wall, so as to simulate the actual conditions of creating street art as much as possible, where the surfaces often present a respectable amount of damage, unevenness and discontinuity.

After the students created the grid, they then continued carefully to transfer the image part by part onto the surface on a larger scale. Due to the fact that they were not familiar with the use of the spray, they decided to create the draft initially with a pastel crayon and then with the spray, so that they would be able to correct the lines in the event of an error. However, a spray can with a colour close to the colour of the wall (light beige) was also available to erase serious mistakes done with the spray.

The total time for the completion of the grid by the students group was 1 hour and 15 minutes, and for the completion of the draft something less than 2 hours. All members of the team worked together for the creation of the grid, while 4 out of 6 members worked on the draft. The grid was a bit difficult for the group to make, mainly due to the texture of the surface of the wall, but also due to the groups' attention to detail (straight lines - correct dimensioning). The group used extensively the light beige spray, correcting many of the lines that did not please them. The final draft of the students was relatively "clean", but there were several erasures and a few smudges. The outlines of the draft were not sufficiently clean and continuous. In general, there were many places in the final draft where the lines did not have the same thickness, or they were fluctuating. 


\subsubsection{Impressions}

The group of students was very enthusiastic about the process and happy to have had the opportunity to participate in this experiment. All members agreed that the use of the grid was necessary, even if it originally seemed to them as a demanding and time-consuming task. One of the group members commented that spray painting turned out to be less difficult than she imagined. All members agreed that working as a team was very helpful for the procedure, even if it caused them to delay, because they could better communicate, point out and correct several of the mistakes that were made. One of the members stated that: "creating the grid helped in the overall design which was closer to the reference image in terms of likeness, while the draft without grid or measurements enabled the artist to personalise the design". Another member testified that: "one of the most crucial elements for better draft creation was the surfaces' condition in addition to the irregularity of the terrain" (angled and rough). Finally, the availability of the spray with the wall colour was something that helped a lot, as they said, but all members acknowledged that in some places the draft deviates from the original, as well as that it is quite different from the design created by the street artist.

\subsection{Creation of the draft sketch by the street artist}

In the second phase of the experiment, after the first draft was completed by the group of students, it was the turn of the street artist to create his draft. In this case, having many years of experience in creating large-scale artwork in the street, graffiti and murals, the artist chose to start creating the draft directly by using the spray and without the aid of a transfer method or by making any measurements on the wall.

Many street artists use chalk or pencil, sometimes a marker or a brush, to have more control over the tool and a margin for avoiding or correcting errors. However, at this stage, the artist chose to use the spray directly, both because he wanted to save time and also because he is an experienced user. The total time the artist needed to complete the draft was 28 minutes, but he also used the light beige spray to correct some of the lines with which he was not content with.

The final draft sketch made by the artist was the one that had the least similarity to the reference picture, compared to the rest. Some elements of the portrait were larger than those in the reference image (eyes, mouth, hair details), and many were positioned differently than the original ones. Also, the artist initially did not create boundaries with which to work within, as did the students, which led him to create a much larger draft than the one the group of students did. On the other hand, what was observed by the participants was the ease and speed with which the draft was completed and the ability to place it on the wall without the need to measure the surface before. The framing of the design in relation to the given surface was also better than that of the students, since the draft sketch was positioned in the centre and almost equidistant from the bottom and top of the wall. Finally, the sketch outlines were quite "clean" and thin, except for the ones surrounding the area of the left eye. The "complexity" of that part of the image possibly was the reason for the untidy outcome. On the final draft there were very few smudges or erasures and there were no drips.

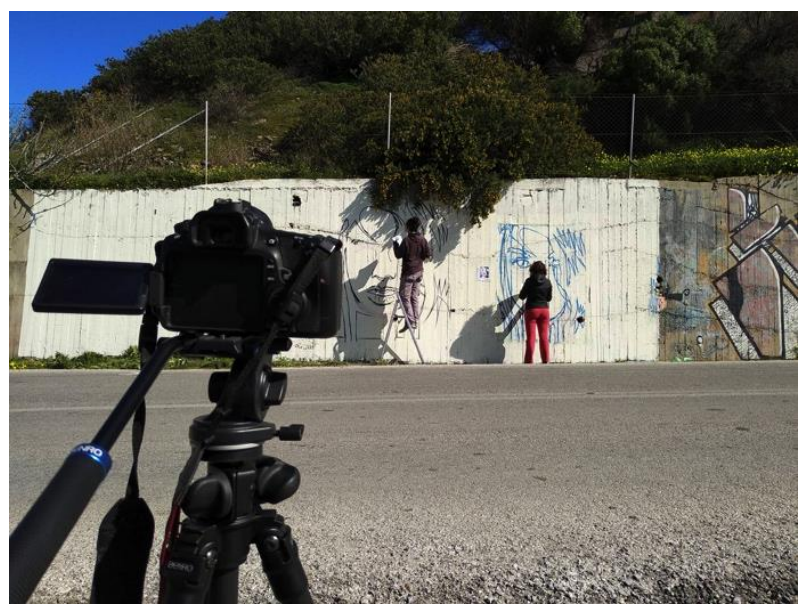

Figure 2: The street artist working on his draft, while a student completes the team's sketch.

\subsection{Creation of the draft sketch by the DDArtS V3}

Last but not least, the DDArtS system was used for the draft creation. The third version (V3) of the system includes some updated elements:

- A spray cap pressure lever that can cause the system to stop and start spraying.

- Ability to implement more complex images from Version number 2.

- A new body kit and sophisticated assemblage to make the system lighter and faster.

Initially, the system had to be assembled and put into operation. In the days before the initiation of the experiment, the system was programmed for the creation of the portrait. Although the ability to read and process files from design software is one for the priorities for the system's optimization, this ability has not yet been adapted to it.

It was decided that the DDArtS system would not be operated directly on the same wall that the 
students and the artist worked, but instead on paper, that would later be pasted on the wall. The reason this decision was supported is that the system has not yet reached its optimal state and any error or malfunction while operating on the wall would be quite time consuming in its correction. Moreover, using a paper to create a draft and then paste it on the wall would give exactly the same outcome for observation and analysis without the risk of causing a problem in the process that would seriously postpone the experiment. Having the painted draft on the paper as a guide, the students and the street artist were able to work on completing the third mural.

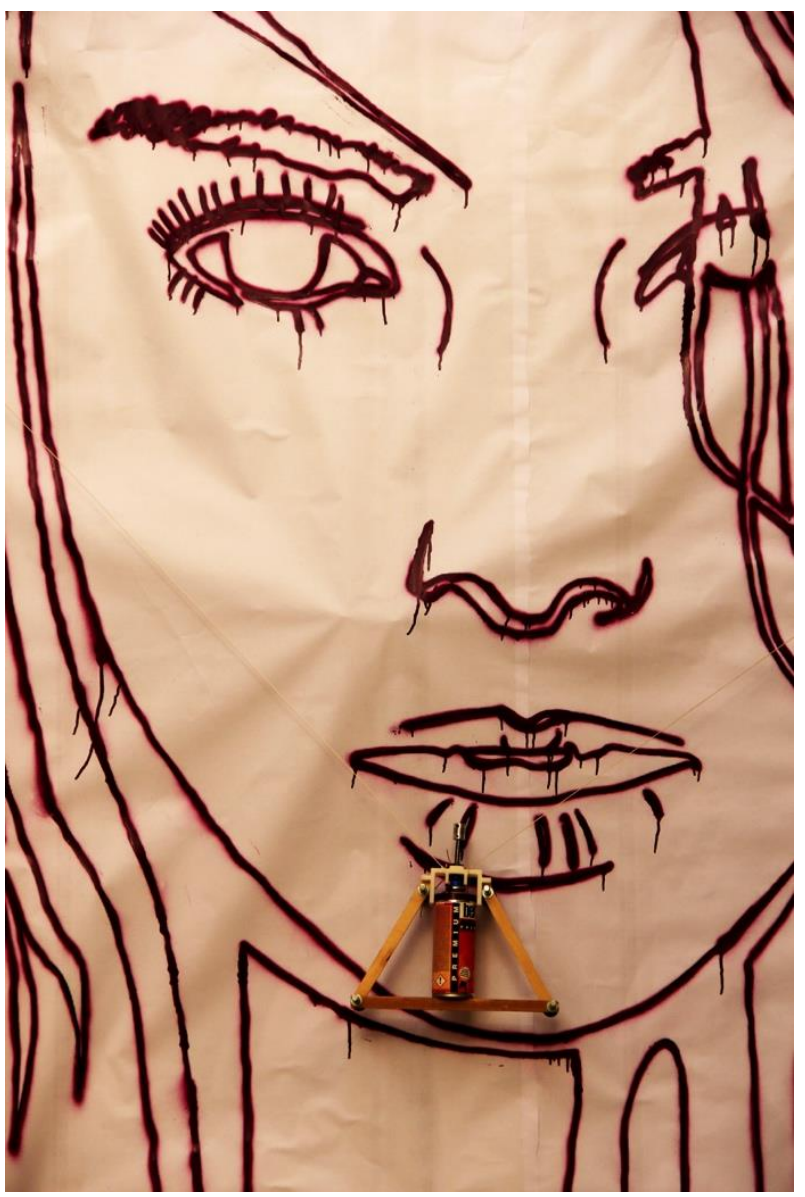

Figure 3: The third draft completed by the DDArtS V3.

After its proper calibration and some unsuccessful attempts, the DDArtS eventually sprayed the draft on the paper, at a total time of 12 minutes. The time spent setting up the system and to have it to start working, without counting the failed attempts, was approximately 15 minutes. The draft that the system produced was the best of the three compared to the original image. The outlines were thicker than of the previous drafts created on the last two phases, but this was not necessarily considered as a positive or a negative feature of the draft. Fact is that the lines were quite clean and there were no smudges, or any other stain. There were some drips in some places, but it is not clear if they were caused by spray or system malfunction.

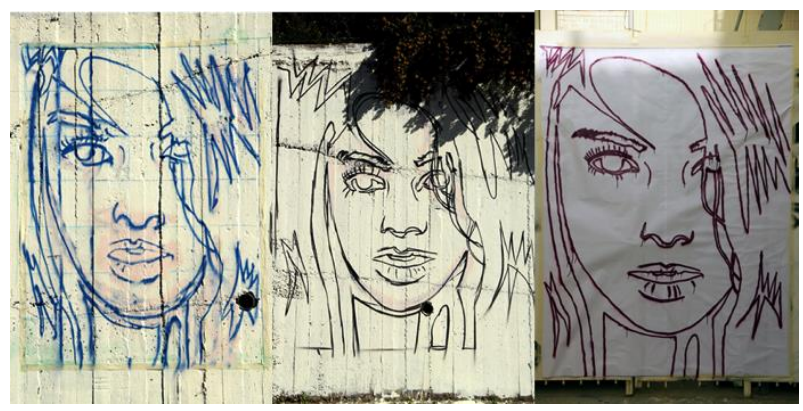

Figure 4: Different completed drafts. From left to right: a) by the students, b) by the artist and c) by the DDArtS V3.

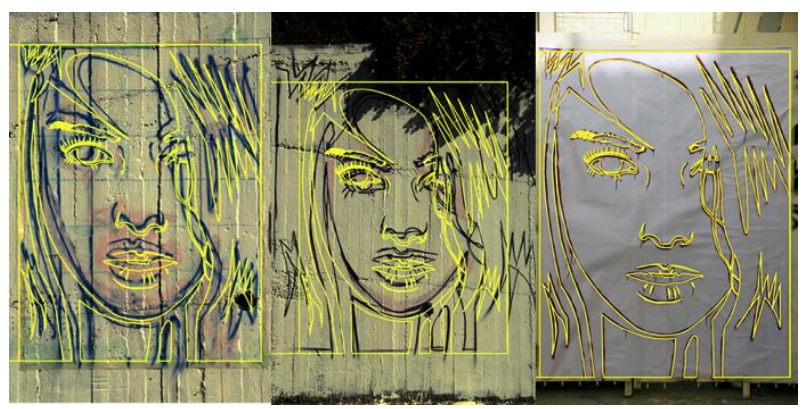

Figure 5: Different completed drafts compared to the outlines of the reference image. From left to right: a) by the students, b) by the artist and c) by the DDArtS V3.

\section{DRAFTS AND FINAL ARTWORKS COMPARISON}

After the completion of all three draft sketches, the students and the artist worked to complete the wall paintings. As stated above, the goal was not to create an identical mural-portrait copy of the reference picture. That is why the participants were encouraged to work freely, without any limitations on the quality and quantity of the colour shades or the artistic approach they wanted to achieve, be it photorealistic, cartoon-like, abstract or else. The only instructions were to work considering the selected images from Figure 1, as well as to notice if the draft helped them in this task. What was very interesting to observe is that the same basis - the same draft, created with three different approaches - can lead to very different artistic results. What is more, it led to the creation of three totally different faces, even if they were based on the same draft. The participants were able to debate on which case the artistic effect creates the greatest impression.

The time needed to complete the final artworks was not measured or thoroughly examined in the technical criteria of the process, since, as mentioned, the participants worked without pressure or restrictions. In the first two phases where the drafts were created on the wall, the 
participants completed the works, creating two large portraits of a female figure, one slightly bigger than the other. In the case where the DDArtS created the draft, the paper was pasted on the wall and the final artwork was completed there. The students painted the right side of the face and the artist painted the left side. The students completed the portrait in 5 hours, using 3 spray colours, the artist in approximately 4 hours, using 12 different spray colours, and they together finished the last one in 3 hours using 10 different colours.

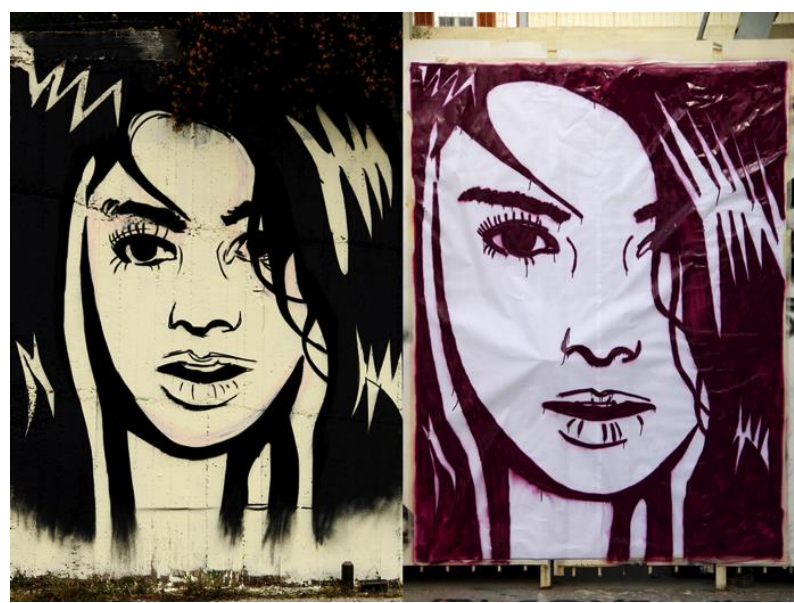

Figure 6: "Filled" drafts compared to each other. From left to right: a) draft created and filled by the artists, b) draft created by the DDArtS and filled by the artist.

By recording the time needed to complete the draft each time, it was found that the DDArtS system was the one that completed the draft faster than in the other two phases. The cumulative results on completion times and the characteristics of the drafts in each phase are shown in Table 1. Green cells are the ones that present the best performance in each case. It can easily be ascertained that the best results, concerning the draft, were produced by the DDArtS. One of the drawbacks of the system is the large amount of time it is required for its setup and calibration.

Of the three drafts, the one most identical to the original image, with almost $100 \%$ likeness, is the draft created with the DDArtS (Figure 5, Table 1). Also, both the group of students and the street artist, after the completion of the artworks, agreed that the draft created by DDArtS was quite useful for rendering the portrait with a right analogy to the facial characteristics of the reference image. It was a "reliable" draft, because based on it, they ensured that the final painting had no mistakes in the analogies between certain elements of the portrait, between the nose and the eyes, for example, which led to a better depiction of shadows and highlights and ultimately, in the development of an accurately structured portrait.
The reason why the rating in the last line of the table is lower for drafts 1 and $2(8 / 10)$ is because some errors in those drafts led to an incorrect display during the process of creating the final project. These errors in the draft cost time to be corrected, which, on the contrary, did not happen with the drafts made by the DDArtS. The final artwork created by the students, the artist and the DDArtS (Figure 7) looks as if an individual has created it; the distinction in the drawing style between the two sides is not clear. The opinion of the participants is that the draft was the reason for this result, since both sides were free to operate as they wished during the painting process.

Table 1: Completion time and quality of the draft for each of the three stages.

\begin{tabular}{|l|c|c|c|}
\hline Draft & $\begin{array}{c}\text { Team of } \\
\text { Students }\end{array}$ & $\begin{array}{c}\text { Street } \\
\text { Artist }\end{array}$ & DDArtS V3 \\
\hline Setup time & 5 minutes & 5 minutes & 15 minutes \\
\hline $\begin{array}{l}\text { Grid } \\
\text { creation } \\
\text { time }\end{array}$ & $\begin{array}{l}1 \text { hour and } \\
15 \text { minutes }\end{array}$ & - & - \\
\hline $\begin{array}{l}\text { Draft } \\
\text { completion } \\
\text { time }\end{array}$ & $\begin{array}{c}1 \text { hour and } \\
50 \text { minutes }\end{array}$ & 28 minutes & 12 minutes \\
\hline $\begin{array}{l}\text { Total time } \\
\text { and } 10 \\
\text { minutes }\end{array}$ & $\begin{array}{c}\mathbf{3 3} \\
\text { minutes }\end{array}$ & $\begin{array}{c}\mathbf{2 7} \\
\text { minutes }\end{array}$ \\
\hline $\begin{array}{l}\text { Draft } \\
\text { outlines } \\
\text { cleanliness }\end{array}$ & $8 / 10$ & $9 / 10$ & $9 / 10$ \\
\hline $\begin{array}{l}\text { Likeness to } \\
\text { the } \\
\text { reference }\end{array}$ & $7 / 10$ & $5 / 10$ & $10 / 10$ \\
\hline $\begin{array}{l}\text { Helpful for } \\
\text { the final } \\
\text { artwork }\end{array}$ & $8 / 10$ & $8 / 10$ & $10 / 10$ \\
\hline
\end{tabular}

However, the participants agreed that the work created by the street artist, even though it was based on the draft that had the least similarity to the original, is the one that created the major visual impact. The artist worked more freely, "shaping" elements of the image in his own personal style and possibly altering or transforming the portrait in the way he wanted it. The artist himself felt that he did not want to alter the draft made by DDARrtS, and in a sense, he was confined to creating the final draft based on the given outlines. This made him work faster and more efficiently, even if he was not as free as he was when he worked on his own artwork. 


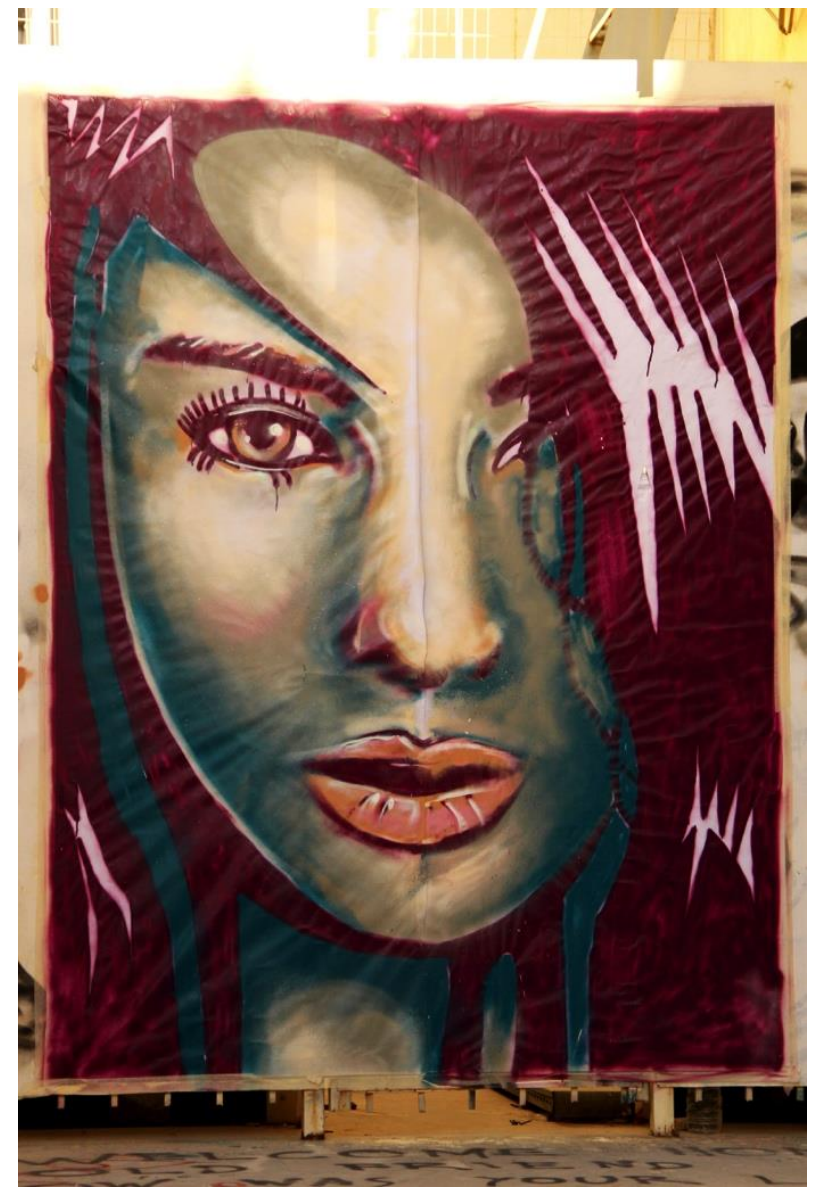

Figure 7: The final artwork based on the DDArtS draft.

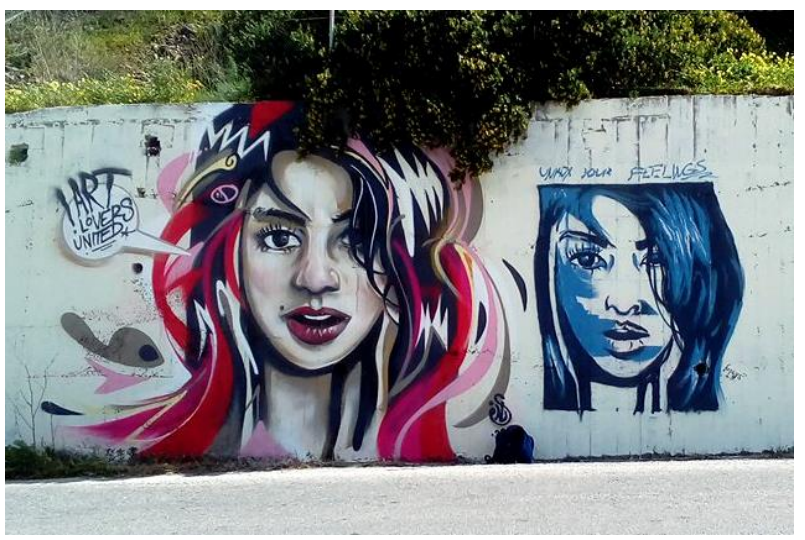

Figure 8: The final artworks of the street artist (left) and the students (right).

\section{CONCLUSIONS AND FUTURE RESEARCH}

The three-phase experiment for the creation of drafts and, eventually, large-scale Artwork projects, met up to the goals originally set. The initial quantitative and qualitative criteria were securely evaluated. Taking into account the views of the participants, conclusions for the success of the process could then be made.
The most important aspect of the experiment, in relation to the goals set in the beginning, was to study whether street art, and more specifically, the creation of murals, can be supported by the design of products and/or systems. To a large extent, this goal has been achieved. The final artwork based on the draft created by DDArtS stands as witness exhibiting two solid reasons that verify why:

- The draft created by the DDArtS succeeded in being identical to the reference image and the less time consuming of the three.

- The final artwork based on the DDArtS draft was created more effortlessly and in confidence that there were no actual orientation errors.

Such errors usually turn up in human operated environments, no matter how experienced an artist or a person is in his art or profession. For a completely accurate draft, especially in large-scale projects, the artist needs to be extremely skilled and spend a respectable amount of time in the making. What is more important though, is that the draft works for the final artwork as the skeleton works for the body. Although it is vitally important for the artwork, in most cases it disappears under the layers of lines, shapes and colours that form the final image. In this regard, it seems only logical that the artist should spent as less time and energy as possible for a part of the process that will not even be visible at the end.

Products, systems, techniques and methods of other interdisciplinary fields can support the multidisciplinary field of Street Art and Design. As happens in graphic design, games design, media design, animation, web design and more, the use of technology, informatics, mechanics, robotics, etc. is a decisive part of the evolution process. The DDArtS is an example of such assistance in the field of street art, even if it only focuses on the draft creation for the moment.

In addition, a significant step in the evolution of the DDArtS will be the comparative study of the results from other systems in development, or already in use, either in scientific / academic environments or for commercial purposes. Such similar work includes the sprayprinter by the Estonian inventor Mikhel Joala, or graffiti artist's KATSU spraying drone. These examples, as well as others, are part of the state of the art in the special field that concerns the support of street art and design with technology and mechanical engineering.

Some of the issues that will be addressed in future research to improve DDArtS include: Optimizing the system in a way that it will require less energy, which will allow it to operate with a portable power transmitter (e.g., battery). Significant optimizations 
have to be made in regard to the weight and volume of the system so that it can be transported and stored more easily. A special case for the transportation of all the necessary equipment for the operation of the system can also contribute to a more effective storage. In future versions, the system should be assembled and disassembled faster, and it should take less for the set-up time on the surface that will function. Also, it should be improved in such a way as to avoid possible wear or inaccuracy, and optimised to be repaired effortlessly. Finally, the number of components and additive manufacturing components from which the system is composed should be bigger. In this way, there may be a limitation on the materials that can be used, but this helps to avoid dependence on spare parts.

\section{ACKNOWLEDGEMENTS}

The authors would like to acknowledge the students participating in the experiment: Ioanna Banou, loanna Maria Mega, Athina Bosta, Zacharenia Badi, Margarita Hadjispyrou, Marina Niksarlidou. We also thank Dr. Spyros Bofylatos for his valuable proofreading, comments and suggestions.

Figure 8 provided by Marina Niksarlidou. All other photographs taken by the authors.

\section{REFERENCES}

Blackshaw, R. and Farrely, L. (2008) Street Art in The Artists' Own Words, Rotovision.

Deitch, J., Gastman, R., and Rose, A. (eds.) (2011) Art in the Streets. Skira

Gray, C. and Malins, J. (2004) Visualizing Research: A guide to the research process in art and design. Art and Design. Ashgate.

ICARUS ONE (2018). http://www.icarusone.com (retrieved 20 March 2018)

Noble, I. and Bestley, R. (2005) Visual Research: An Introduction to Research Methodologies in Graphic Design. AVA.

Sprayprinter (2018). http://sprayprinter.com (retrieved 20 March 2018).

Xyntarianos-Tsiropinas, P., Bailas, K., and Spyrou, T. (2017) The Process of Transferring a Draft Sketch from Small to Large Scale in order to Create Street Artworks: A Case Study Supported by the DDArtS. Electronic Visualisation and the Arts (EVA London 2017).

Xyntarianos-Tsiropinas, P., and Spyrou, T. (2016) DDArtS: Towards designing digitally enhanced street art tools. Electronic Visualisation and the Arts (EVA London 2016). 